\title{
Pontederiaceae do litoral piauiense, Brasil
}

\author{
Pontederiaceae in the coastal region of Piauí, Brazil
}

\author{
Hilda Cristina Evaristo Nascimento ${ }^{1,3}$, Ivanilza Moreira de Andrade ${ }^{1,3}$, Maria Francilene Souza Silva ${ }^{1}$ \\ \& Ligia Queiroz Matias ${ }^{2}$
}

\begin{abstract}
Resumo
O presente estudo apresenta o tratamento taxonômico da família Pontederiaceae no litoral piauiense, contribuindo para o conhecimento da diversidade biológica do estado do Piauí. Foram identificadas cinco espécies distribuídas em três gêneros, Eichhornia Kunth, Heteranthera Ruiz \& Pav. e Pontederia L. Eichhornia foi o mais representativo com três espécies, E. azurea (Sw.) Kunth, E. crassipes (Mart.) Solms e E. diversifolia (Vahl) Urb., enquanto Pontederia e Heteranthera estão representadas por uma espécie, $P$. cordata var. ovalis (Mart.) Solms e H. rotundifolia (Kunth) Griseb., respectivamente. Todas as espécies são nativas, mas não endêmicas da região. Três representam novas ocorrências para o estado. São apresentadas chave de identificação, descrições, ilustrações e informações sobre distribuição geográfica e habitat.

Palavras-chave: Biodiversidade do Piauí, Delta do Parnaíba, macrófitas aquáticas.
\end{abstract}

\begin{abstract}
The taxonomic treatment for the family Pontederiaceae in the coastal region of Piauí is presented as a contribution to knowledge of the biological diversity of the state. Five species were identified in three genera, Eichhornia Kunth, Heteranthera Ruiz \& Pav. and Pontederia L. Eichhornia is represented by three species, E. azurea (Sw.) Kunth, E. crassipes (Mart.) Solms and E. diversifolia (Vahl) Urb., while Pontederia and Heteranthera are represented by a single species each, P. cordata var. ovalis (Mart.) Solms and H. rotundifolia (Kunth) Griseb., respectively. All species are native but not endemic to the region. Three species are new records for Piauí. Descriptions, illustrations and an identification key to the species are provided, together with information on their geographical distribution and habitats.
\end{abstract}

Key words: Aquatic macrophytes, biodiversity of Piauí, Delta do Parnaíba.

\section{Introdução}

Pontederiaceae compreende cerca de nove gêneros e 33 espécies, distribuídas em três tribos: Eichhornieae (Eichhornia Kunth e Monochoria C.), Heteranthereae (Eurystemon Alexander, Heteranthera Ruiz \& Pav., Hydrothrix Hook. f., Scholleropsis H. Perrier e Zosterella Small) e Pontederieae (Pontederia L. e Reussia Endl.) (Cook 1998; Graham et al. 1998; Simpson \& Burton 2006). Apresenta distribuição pantropical, com muitos membros ocorrendo principalmente na região Neotropical e poucas espécies registradas para o norte e sudeste do Canadá, sul e sudeste da Argentina. Outras espécies são encontradas no Sul da África, Madagascar, Sudeste da Ásia e Austrália (Simpson
$\&$ Burton 2006). No Brasil ocorrem cinco gêneros (Eichhornia, Heteranthera, Hydrothrix, Pontederia, Reussia) e 19 espécies, das quais duas endêmicas: Hydrothrix gardneri Hook.f. e Pontederia triflora (Seub.) G. Agostini, D. Velásquez \& Velásquez (Amaral 2012; Gastal Júnior 1999).

Levantamentos florísticos constituem importante fonte de dados para a conservação, bem como para a exploração racional dos recursos e das áreas naturais ainda existentes. Levantamentos sobre a família Pontederiaceae no Brasil foram realizados para Santa Catarina (Castellanos 1967); Rio Grande do Sul (Irgang et al. 1984); Mato Grosso do Sul (Pott \& Pott 1997, 1999; Rocha et al. 2007); Mato Grosso (Sanches et al. 2000); Rio de Janeiro (Bove

\footnotetext{
'Universidade Federal do Piauí, Campus de Parnaíba, Herbário Delta do Parnaíba, Av. São Sebastião 2819, 64202-020, Parnaíba,PI, Brasil.

${ }^{2}$ Universidade Federal do Ceará, Centro de Ciências, Depto. Biologia, Centro de Ciências, bl. 906, Campus do Pici, 60451-760, Fortaleza, CE, Brasil.

${ }^{3}$ Autor para correspondência: ivanilzaandrade@hotmail.com
} 
et al. 2003) e Minas Gerais (Trovó \& Gomes-Silva 2010). Para a Região Nordeste, Pontederiaceae é citada apenas em levantamentos mais abrangentes ou de floras aquáticas (França et al. 2003; Matias et al. 2003; Neves et al. 2006; Henry-Silva et al. 2010; Lyra-Lemos et al. 2010, Sobral-Leite et al. 2010).

O Delta do Parnaíba e seus cordões arenosos formam um sistema estuarino complexo associado às lagoas costeiras e campos inundados (Martins \& Coutinho, 1981). Mas, apesar de sua importância para a manutenção da biodiversidade, o Delta do Parnaíba não consta entre os importantes sítios internacionais anotados pela Convenção sobre Áreas Alagadas de Ramsar (Kingsford 1997; Ramsar 2010). Este trabalho teve como objetivo identificar os táxons de Pontederiaceae que ocorrem no litoral piauiense, fornecendo informações sobre a flora desta extensa área alagada. Esperamos que os resultados possam auxiliar o desenvolvimento de estratégias para manejo e uso sustentável dos recursos naturais desta região.

\section{Material e Métodos}

Os espécimes analisados foram provenientes de coletas mensais realizadas durante o período de julho de 2010 a outubro de 2011 nos municípios do litoral piauiense (Cajueiro da Praia, Ilha Grande, Luis Correia e Parnaíba), além de material depositado nos herbários EAC, HUVA e TEPB (acrônimos segundo Holmgren et al. 1990).

O Piauí, com sua faixa litorânea de $66 \mathrm{~km}$ de extensão, faz divisa com o Maranhão, na Barra das Canárias, e segue pela Ilha Grande de Santa Isabel, passando pelo farol e praia da Pedra do Sal, até a Barra da Timonha - na foz do rio São João da Praia, na divisa com o Ceará. O litoral Piauiense abrange os municípios de Cajueiro da Praia, Ilha Grande do Piauí, Luís Correia e Parnaíba, ocupando uma área de aproximadamente $571.071 \mathrm{~km}^{2}$. O clima é quente e úmido, com chuvas de verão e temperaturas médias anuais em torno de $26^{\circ} \mathrm{C}$ e totais pluviométricos em média $1.200 \mathrm{~mm}$ (Rizzini 1997; Fernandes 2000; Zickel et al. 2007).

A paisagem litorânea piauiense é formada pelo predomínio de sedimentos Quaternários compondo três unidades geomorfológicas: faixa de praia e dunas, planície flúvio-marinha e planície fluvial. Há também a formação Terciária dos tabuleiros costeiros e os Maciços Residuais dos Granitos de Chaval (Chaves et al. 2007). A vegetação tem influência marinha (restingas e dunas), flúvio-marinha (manguezais e campos salinos) e fluvial (comunidades aluviais). Tais formações predominam na paisagem e dividem espaço com outras formações arbóreas, como os tabuleiros litorâneos, a caatinga e o cerrado (Fernandes 2000; Veloso et al. 1991).

Os espécimes coletados foram herborizados seguindo a metodologia de Haynes (1984) e depositados no herbário TEPB, EAC e HDELTA. As formas biológicas foram classificadas segundo Irgang \& Gastal Júnior (1996). A identificação foi realizada a partir de literatura específica (Lowden 1973; Sanches et al. 2000; Moretti 2003) e comparação com materiais previamente identificados e revisados por especialistas. As espécies foram descritas e ilustradas de maneira convencional utilizada em taxonomia. Os nomes dos táxons foram atualizados de acordo com o banco de dados do IPNI (The International Plant names Index) e WCSP (World Checklist of Selected Plant Families).

\section{Resultados e Discussões}

Foram identificadas cinco espécies pertencentes aos gêneros Eichhornia, Heteranthera e Pontederia. Eichhornia foi o mais representativo com três espécies, E. azurea (Sw.) Kunth, E. crassipes (Mart.) Solms e E. diversifolia (Vahl) Urb. Heteranthera e Pontederia estão representados por uma espécie $H$. rotundifolia (Kunth) Griseb. e $P$. cordata var. ovalis (Mart.) Solms, respectivamente. Todas as espécies são nativas e não endêmicas. Com exceção de $E$. crassipes e $H$. rotundifolia, todas as espécies são novos registros para o estado do Piauí.

A análise de material dos herbários e da literatura revelou poucos registros de $E$. diversifolia tanto para o estado do Piaú, quanto para outros estados. É possível que esta espécie seja rara ou esteja ameaçada de extinção em virtude da destruição de seus habitats. Por outro lado, é possível que a lacuna de conhecimento e registros das mesmas sejam devido ao baixo esforço de coleta. Estudos taxonômicos com Pontederiaceae são ainda escassos no Brasil. Atualmente, na Região Nordeste são reconhecidos seis gêneros e 10 espécies (Amaral 2012).

O número de espécies encontradas na área de estudo evidencia a notada baixa diversidade de Pontederiaceae quando comparado com os números registrados em outros trabalhos realizados em lagoas e rios no Brasil. No checklist das macrófitas de Pernambuco, as Pontederiaceae estão representadas por 10 espécies, o maior número de espécies já registrado para o Nordeste (Sobral-Leite et al. 2010). Espécies ocorrentes em Pernambuco e na área deste estudo foram: Eichhornia crassipes, 
E. diversifolia e Pontederia cordata var. ovalis. França et al. (2003) registraram número menor de espécies (três) em açudes de uma região do semiárido da Bahia. Este registro foi corroborado mais tarde por Henry-Silva et al. (2010).

Os gêneros Eichhornia, Heteranthera e Pontederia também foram registrados para o Pantanal onde há maior diversidade de espécies (11 espécies). Com exceção de $H$. rotundifolia, todas as demais espécies identificadas para o litoral piauiense ocorrem no Pantanal, mais as seguintes: E. meyeri A. G. Schultz, H. limosa (Sw.) Willd., $H$. multiflora (Griseb.) Horn, P. cordata var. lancifolia (Muhl.) Torrey, P. rotundifolia L.f., P. subovata (Seubert) Lowden. e P. triflora (Seubert) Agostini, D. Velásquez \& J. Velásquez (Pott \& Pott 1997).

\section{Tratamento taxonômico}

Pontederiaceae Kunth in F. A. H. A. Humboldt, A. J. A. Bonpland \& C. S. Kunth, Nova Gen. Sp. 1: fol. 211 ed. 4: 265. 1816

Ervas aquáticas, rizomatosas ou estoloníferas, flutuantes a emersas, raro submersas, caules esponjosos. Folhas geralmente alternas e espiraladas, ao longo do caule ou mais ou menos basais, simples, inteiras, com venação paralela a palmada, invaginantes na base; estípulas ausentes. Inflorescência determinada, mas frequentemente parecendo racemo ou espiga, às vezes parecendo lateral, associada com duas brácteas, raro uniflora. Flores bissexuais, radiais a bilaterais, com frequência apresentando tristilia. Tépalas 6 , vistosas, variavelmente conatas, imbricadas, as tépalas adaxiais do verticilo interno com freqüência diferenciadas. Estames geralmente seis; filetes adnatos ao tubo do perianto, com frequência apresentando comprimentos desiguais; anteras deiscentes por fenda ou poros; grão de pólen com um ou dois sulcos. Carpelos 3, conatos, ovário súpero com placentação axial, ocasionalmente parietal com placenta intrusiva, às vezes com dois lóculos estéreis; estigma capitado a 3-lobado; óvulos um a numerosos por lóculo; nectários frequentemente presentes nos septos do ovário. Fruto cápsula loculicida, utrículo ou noz, rodeado por uma porção persistente do tubo periântico.

\section{Chave para identificação para os táxons de Pontederiaceae do Delta do Parnaíba, Piauí}

1. Plantas com flores azuis a lilases; ovário trilocular; fruto cápsula com numerosas sementes.

2. Folhas sésseis ou pecioladas, planta multiflora, flor com seis estames.

3. Planta com folhas lanceoladas, espatuladas, ovadas ou reniformes, inflorescência com mais de 10 flores, escapo floral $11-70 \mathrm{~cm}$ compr.

4. Lâmina foliar espatulada, tépalas internas com margem fimbriada

4'. Lâmina foliar reniforme, tépalas internas com margem inteira 1.1. Eichhornia azurea 1.2. Eichhornia crassipes

3'. Planta com folhas cordatas, inflorescência com duas a três flores, escapo 1,1-2,2 cm compr. .... 1.3. Eichhornia diversifolia

2'. Folhas pecioladas, planta uniflora, flor com três estames ............. 2.1. Heteranthera rotundifolia 1'. Plantas com flores alvas; ovário unilocular; fruto utrículo ............ 3.1. Pontederia cordata var. ovalis

1. Eichhornia Kunth, Enum. P1. 4: 129. 1843.

Plantas anuais ou perenes, flutuantes livres a enraizadas. Caules flutuantes a eretos, rizomatosos a estoloníferos. Folhas sésseis formando uma roseta basal ou alternas ao longo do caule; folhas pecioladas flutuantes ou emersas, cordadas, cordado-lanceoladas, ovalacuminadas obovadas, orbiculares elípticas. Inflorescência espiciforme a paniculada. Flores tubulares, zigomorfas, coloração azul a roxo. Tépalas oblongo-lanceoladas, glandular-pubescentes, com margens inteiras ou fimbriadas. Androceu com seis estames, sendo os três superiores mais curtos que os três inferiores. Estilete pubescente a pilosoglandular, homostílico ou heretostílico. Fruto cápsula loculicida, sementes numerosas.

Eichhornia é um gênero nativo de regiões tropicais e subtropicais da América, com uma espécie (E. diversifolia) também na África tropical, diferente de Pontederia que é gênero exclusivamente americano (Dahlgren et al. 1985). 
1.1. Eichhornia azurea (Sw.) Kunth, Enum. Pl. 4: 129. 1843. Figs. 1a-b; 3a-b

Planta flutuante fixa, ca. $70 \mathrm{~cm}$ compr. Folhas emersas, glabras, pecíolo não inflado $9-15 \mathrm{~cm}$ compr., cilíndrico, esponjoso; bainha 2-7 × 1,2-3 cm; lâmina foliar 3-3,4 × 12,6-14,2 cm, cartácea, espatulada, base atenuada, ápice agudo, margens inteiras. Escapo 11,2-13,5 cm compr.; brácteas espatuladas 2-4,2 × 1,2-1,7 cm. Inflorescência espiga, glabra, 18 a 26 flores. Flores azuladas, guia de néctar mais intensamente azulado em um terço na porção próxima. Tépalas pilosas, as internas fimbriadas 1,3-2,1 cm compr. Estames 6, com até $1 \mathrm{~cm}$ compr., concrescidos às tépalas, inseridos na parte superior do tubo da corola, anteras oblongas. Gineceu 2,1-2,9 cm compr.; ovário 4-6 mm, estilete 1,7-2 cm, piloso, heterostílico; estigma tripartido e pubescente. Fruto 1,6-1,9 cm compr. Semente ca. 2 $\mathrm{mm}$, achatada lateralmente, apiculada, creme.

Material examinado: Cajueiro da Praia, Boa Vista, 31. VIII. 2011, fl., M.F. Silva et al. 38 (TEPB).

Material adicional: Campo Maior, Açude do Urum, 20.V.2008, fl., F.O. Pires et al. 88 (EAC); Campo Maior, 25. IV. 2004, fl., L.P. Felix 25 (EAC). PARÁ: Rio, 11.XI.1987, fl., H.A. Beck, et al. 405 (EAC); BAHIA: Barra, Margem Rio Grande, 11.V.2003, fl., V. Gomes 32551 (EAC).

Eichhornia azurea foi encontrada em campos alagados e em lagos de várzea. Segundo Moretti et al. (2003), esta espécie está associada a abundância de macroinvertebrados que ficam distribuídos entre seus ramos ou na área de superfície foliar. Difere de $E$. crassipes pelas tépalas pilosas com margens fimbriadas, enquanto E. crassipes apresentam margens inteiras (Sanches 2000). Segundo Amaral (2012) a espécie é nativa e não endêmica, ocorre na região Norte (RR, AP, PA, AM, TO, RO), Nordeste (MA, CE), Centro-Oeste (MT, MS), Sudeste (MG, $\mathrm{SP}, \mathrm{RJ}$ ) e Sul (SC, RS), na Amazônia, Caatinga, Cerrado, Mata Atlântica e, Pantanal. Este é o primeiro registro para o estado do Piauí.

1.2. Eichhornia crassipes (Mart.) Solms, in A. DC. \& DC., Monogr. Phan. 4: 527. 1883.

Figs. 1c-d, 3c-d.

Planta flutuante livre ou fixa, ca. $80 \mathrm{~cm}$ de altura em águas rasas. Folha 6,8-7 × 11,5-12 $\mathrm{cm}$, reniforme, ápice arredondado, base cuneada, cartácea, margem inteira; pecíolo 4-11,0 × 1,4$26,3 \mathrm{~cm}$ compr., inflado, cilíndrico, esponjoso. Inflorescência espiga, de 10 a 26 flores; escapo $35-70 \mathrm{~cm}$ compr. Flores lilases, ca. 2,7 cm compr. Tépalas 6, 2,3-3,3 cm compr., a superior com guia de néctar vináceo com centro amarelo, margens inteiras. Estames 6, filetes pilosos, anteras oblongas. Gineceu 1-3,1 cm compr.; ovário 0,5-7 cm compr., estilete piloso $0,7-2,8 \mathrm{~cm}$ compr., tripartido. Fruto 1,7-2 cm compr. Semente $1 \mathrm{~mm}$, creme.

Material examinado: Parnaíba, Antigo do Braço do Rio Igaraçu, 31.VIII.2011, fl. e fr., H.C.E. Nascimento 132 (TEPB); Parnaíba, Capinzal, 29.IV.2011, fl., H.C.E. Nascimento 100 (TEPB); Parnaíba, Capinzal, 29.IV.2011, fl., H.C.E. Nascimento 105 (TEPB); Parnaíba, Lagoa do lava jato, 29.VIII.2011, fl., H.C.E. Nascimento 123 (TEPB); Parnaíba, Antigo do Braço do Rio Igaraçu, 31.VIII.2011, fl., H.C.E. Nascimento 133 (TEPB); Parnaíba, Capinzal, 29.IV.2011, fl., H.C.E. Nascimento 109 (TEPB); Parnaíba, Capinzal, 29.IV.2011, fl. e fr., H.C.E. Nascimento 91 (TEPB). Parnaíba, Ilha das Batatas, 20. IX. 1987, fl., M.G.M. Arraias 6080 (TEPB). Material adicional: ALAGOAS: Piraçubuçu, Fazenda Batinga, 3.V.1983, fl. R.F.A. Rocha 536. (TEPB); Batalha, Parque Ambiental Paquetá, 18.III.2006, fl. L. Oliveira 21 (TEPB). CEARÁ: Iguatu, Lagoa do Saco, 14.V.2011, fl., L.R.O. Normando 116 (EAC); Iguatu, Lagoa do Baú, 30.VI.2010, fl., J.R.A. Paiva \& L.Q. Matias 04 (EAC).

O pecíolo inflado e a tonalidade lilás da flor desta espécie dependem da quantidade de nutrientes do ambiente onde as populações se desenvolvem (Sanches 2000). Foi encontrada nas margens de rios, igarapés e lagoas temporárias eutrofizadas, tendo sido registrada anteriormente por Sousa (2010) para o litoral piauiense. Devido ao seu rápido crescimento, tendem a formar uma cobertura homogênea sobre a lâmina dos sistemas aquáticos. Entretanto, pode ser utilizada como ferramenta importante na restauração de sistemas hipereutróficos onde o crescimento pode ser controlado mecanicamente (Meerhoff et al. 2002). É relatado o uso em tratamento de efluente, de curtume de peles de tilápias e em artesanato em um Distrito do Pantanal (Chaguri 2010), como alimento para o peixe-boi e como fertilizante vegetal ou em biodigestores na produção de biogás como fonte alternativa de energia em substituição ao gás derivado de petróleo (Albuquerque 1981).

É nativa e não endêmica. Registrada para a Região Norte (AM), Nordeste (MA, PE, BA), Centro-Oeste (MT, DF, MS), Sudeste (SP), Sul (PR, $\mathrm{SC}$ ), com ocorrência na Amazônia, Cerrado e Mata Atlântica (Amaral 2012).

1.3. Eichhornia diversifolia (Vahl) Urb., Symb. Antill. 4: 147. 1903.

Figs. 1e-i; 3e-f

Planta flutuante fixa, ca. $20 \mathrm{~cm}$ compr. Bráctea 3-4 cm, espatulada. Folhas submersas, 0,5-0,7 × 0,2-0,8 cm, lineares, glabras, cartáceas, ápice agudo, base atenuada, margem inteira; 

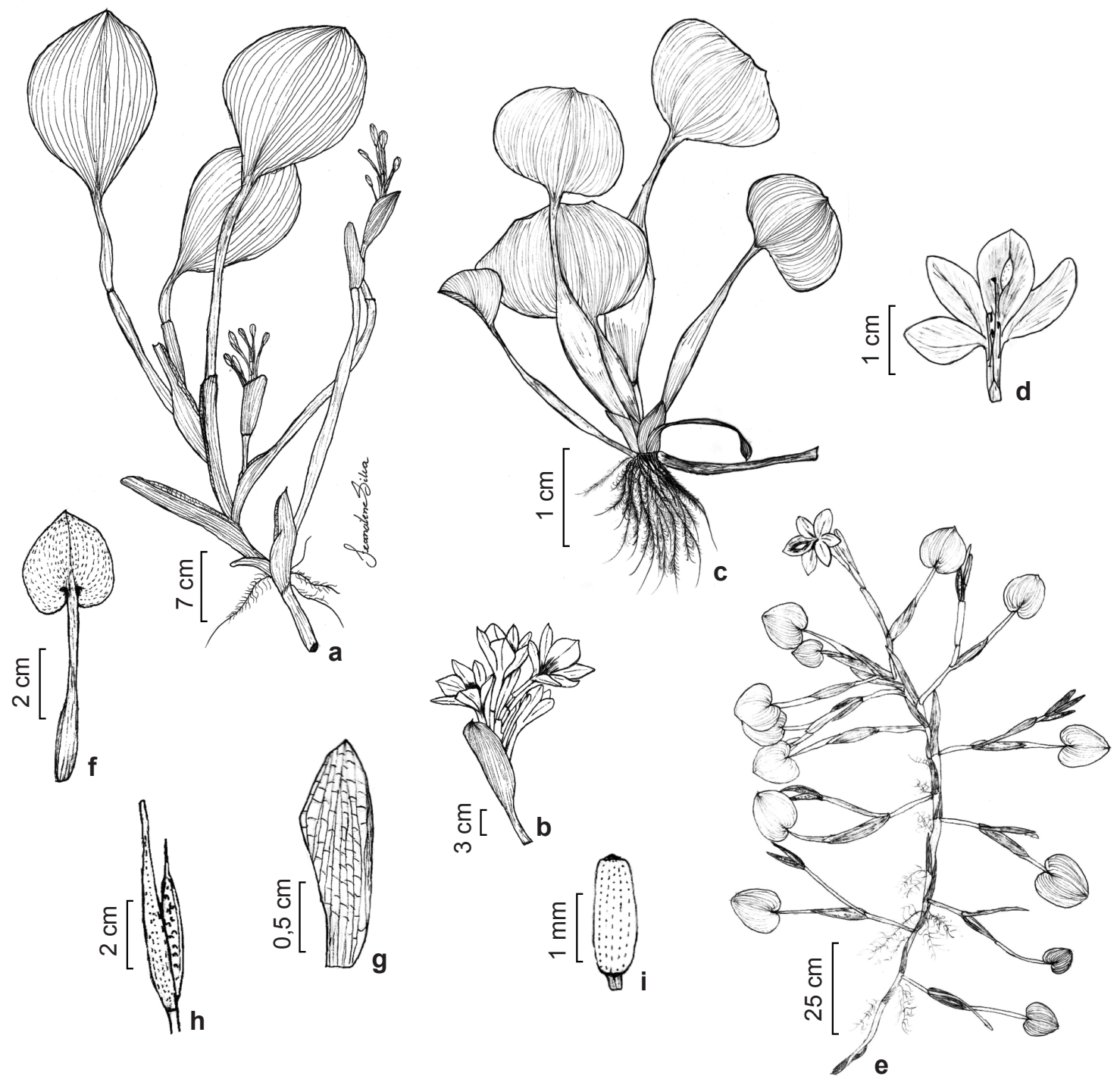

Figura 1 - Pontederiaceae. a-c. Eichhornia azurea (Sw.) Kunth - a. hábito; b. inflorescência (Silva 383); c-d. Eichhornia crassipes (Mart.) Solms - c. hábito; d. flor (Nascimento 132); e-i. Eichhornia diversifolia (Vahl) Urb. e. hábito; f. folha; g. bráctea foliar; h. fruto; i. semente (Araújo 98).

Figure 1 - Pontederiaceae. a-c. Eichhornia azurea (Sw.) Kunth - a. habit; b. inflorescence (Silva 383); c-d. Eichhornia crassipes (Mart.) Solms. - c. habit; d. flower (Nascimento 132); e-i. Eichhornia diversifolia (Vahl) Urb. - e. habit; f. leaf; g. bract; h. fruit; i. seed (Araújo 98).

folhas emergentes cordiformes, ápice obtuso, base cordada, margem inteira; pecíolo 3,7-7 $\times$ 0,3-1 cm compr., cilíndrico, esponjoso; bainha 0,4-2,4 × 0,6-4,1 cm. Inflorescência espiga, glabra; escapo 1,1-2,2 cm compr.; brácteas espatuladas $1,7-1,9 \times 0,5-0,7 \mathrm{~cm}$. Flores 2-3; pedicelo $0,7-1,7$ cm compr.; tépalas azuis, zigomorfas, guias de néctar amarelos em um terço da porção proximal. Estames 6, ca. 1,0 cm compr., concrescidos às tépalas, inseridos na parte superior do tubo da corola, anteras oblongas. Gineceu 2,1-2,4 cm compr.; ovário $0,5-0,6 \mathrm{~cm}$ compr., estilete piloso 1,5-1,7 cm compr., heterostílico; estilete com estigma tripartido, pubescente. Fruto cápsula 1,5-1,7 cm compr. Semente ca. $2 \mathrm{~mm}$, com cristas longitudinais, marrons.

Material examinado: Cajueiro da Praia, Boa Vista, 14.V.2011, fl. e fr., L. Araújo 98 et. al. (TEPB); Parnaíba, Boa Hora, Margem do Rio Longá, 14.IV.1999, fl. e fr., R.A. França (TEPB).

Espécie encontrada em lagoa temporária, somente na estação chuvosa. Distingue-se das demais espécies por apresentar duas a três flores 

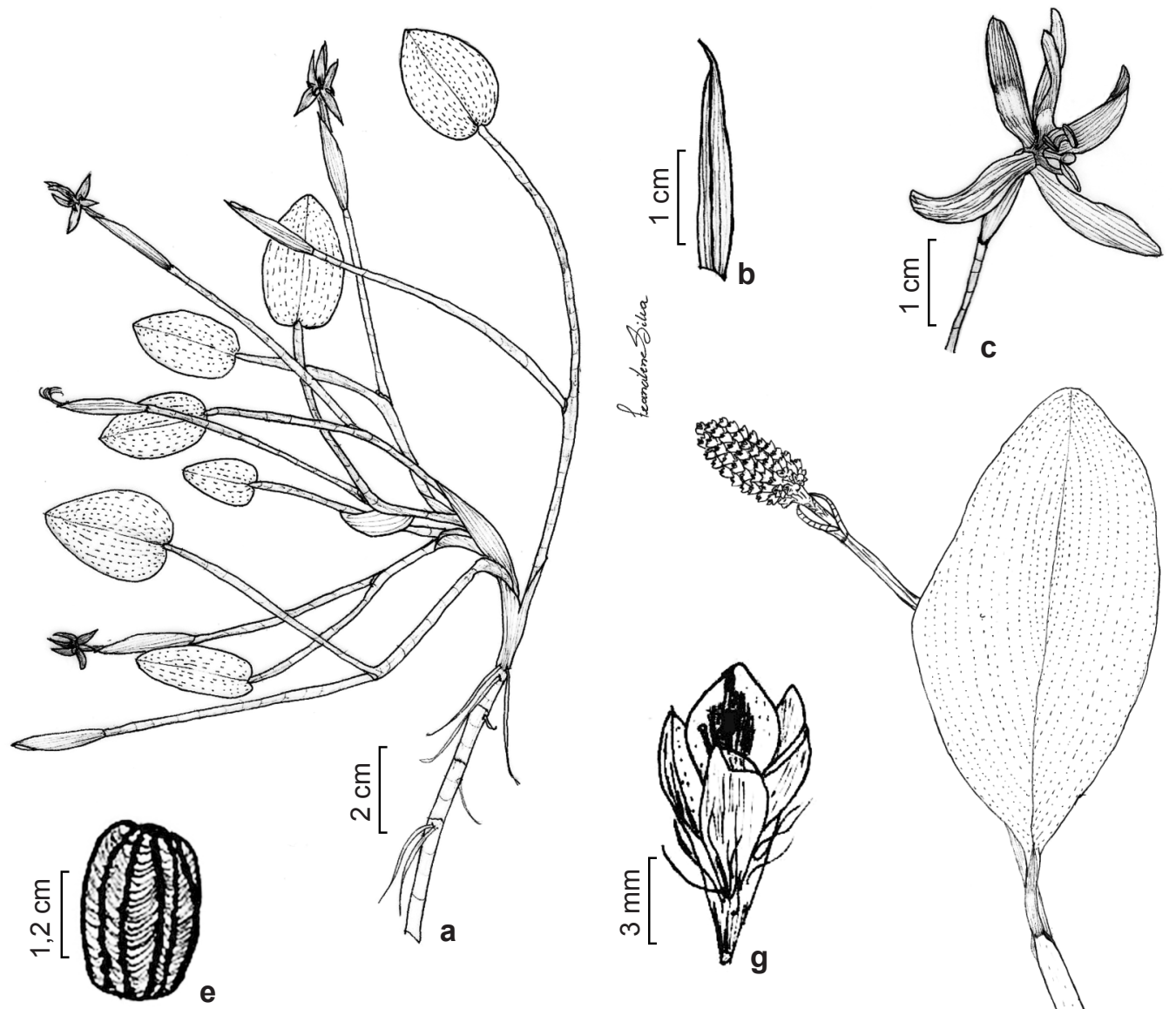

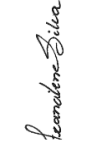
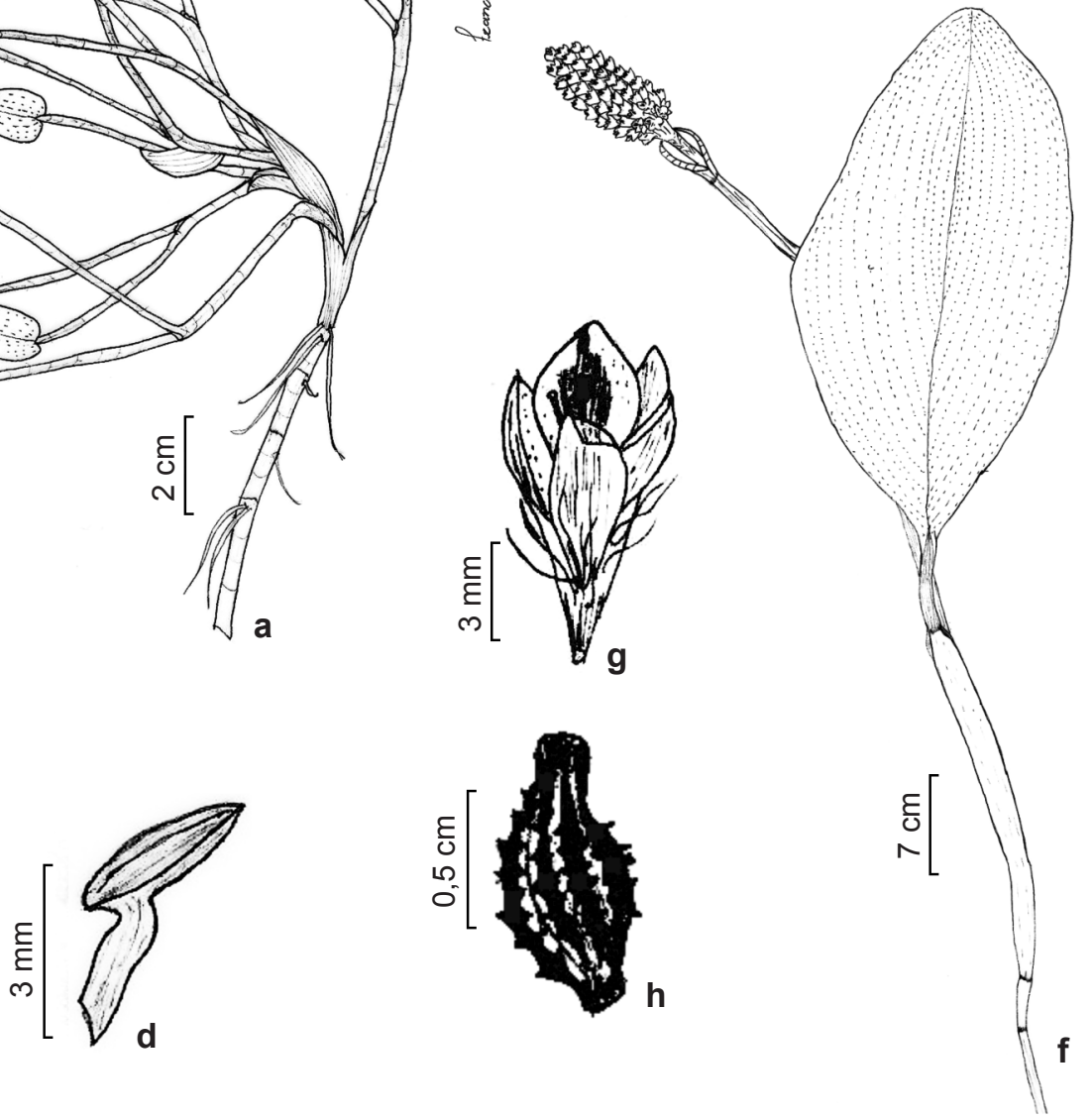

Figura 2 -Pontederiaceae - a-e. Heteranthera rotundifolia (Kunth) Griseb - a. hábito; b. bráctea da inflorescência; c. flor; d. estame; e. semente (Carneiro et al. 34). f-h. Pontederia cordata var. ovalis L. - f. hábito; g. flor; h. fruto (Nascimento 130). Figure 2 - Pontederiaceae - a-e. Heteranthera rotundifolia (Kunth) Griseb - a. habit; b bracts of the inflorescence; c. flower; d. stamen; e. seed (Carneiro et al. 34). f-h. Pontederia cordata var. ovalis L. - f. habit; g. flower; h. fruit (Nascimento 130).

e por folhas de forma ovadas, orbiculares ou reniformes com base cordata nas emergentes e lineares e membranáceas nas submersas (Sanches et al. 2000).

É nativa e não endêmica. Registrada para o Norte (PA, TO, AC), Nordeste (MA, CE, PB, $\mathrm{PE})$, Centro-Oeste (MT, GO) e Sudeste (MG, RJ). Ocorre na Amazônia, Caatinga, Cerrado e Mata
Atlântica (Amaral 2012). A espécie está sendo registrada pela primeira vez para o estado do Piauí.

2. Heteranthera Ruiz \& Pav. Fl. Peruv. Prodr.: 9. 1794.

Plantas anuais ou perenes. Folhas submersas lineares ou emergentes ovadas, elípticas, reniformes a orbiculares; pecíolo nunca inflado. Inflorescência 
uniflora a multiflora, séssil ou pedunculada. Flores zigomorfas. Perigônio hipocrateriforme, tépalas lineares a lanceoladas, as três externas mais estreitas do que as internas, margem inteira. Androceu com três estames, dimórficos, pilosos a glabros; filetes pilosos ou glabros; anteras heteromorfas. Ovário unilocular; estilete glabropubescente. Fruto cápsula.

Heteranthera distingue-se de Eichhornia e Pontederia por apresentar inflorescências unifloras a multifloras e possuir apenas três estames (Sanches et al. 2000).

2.1. Heteranthera rotundifolia (Kunth) Griseb., Cat. Pl. Cub.: 252. $1866 . \quad$ Figs. 2a-e; 3g-h

Planta emergente, ca. $20 \mathrm{~cm}$ compr. Folha emersa, cartácea, $1,2-2,5 \times 0,8-1,6 \mathrm{~cm}$, oval, cordiforme a subcordadas, base cordada, ápice variando de obtuso a arredondo, margem inteira; pecíolo 3,2-8,4 × 0,3-0,8 cm, cilíndrico, oco; bainha $0,2-0,5 \mathrm{~cm}$ compr. Inflorescência uniflora; escapo 1,5-4,8 cm compr.; bráctea linear 1,2-1,9 $\times 0,4-0,5 \mathrm{~cm}$. Flor $1,2-3,1 \times 0,5-1,5 \mathrm{~cm}$, glabra; tépalas $1,8-2,9 \mathrm{~cm}$ compr., azuis, guia de néctar amarelo em um terço da porção proximal, apêndices laterais amarelos na tépala mediana superior. Estames 3, concrescidos às tépalas na base, anteras linear-lanceoladas. Gineceu 0,9-2,6 $\mathrm{cm}$, ovário $0,8-1,1 \mathrm{~cm}$ compr., pluriovulado, placentação central axial, estilete glabro, 0,8-1,2 $\mathrm{cm}$, estigma tripartido. Fruto $1,3-2,1 \mathrm{~cm}$ compr. Semente $0,5-1 \mathrm{~mm}$, com cristas longitudinais, marrom brilhante.

Material examinado: Cajueiro da Praia, Boa Vista, 21.IV.2012. fl. e fr., S. M. G. Carneiro et al. 34 (TEPB); Canto Grande, 20.IV.2012. fl. e fr., S. M. G. Carneiro et al. 35 (TEPB).

Heteranthera rotundifolia é uma espécie estreitamente relacionada à $H$. limosa (Sw.) Willd., tanto que Correll \& Correll (1972) não identificaram caracteres vegetativos que as pudessem diferenciar. Estudos organogênicos conduzidos por Horn (1988) indicaram que plântulas de $H$. rotundifolia possuem pecíolos flexíveis e caules alongados, enquanto que em $H$. limosa os pecíolos são rígidos mesmo quando submersos e raramente desenvolvem caules alongados. Nós observamos que os apêndices laterais amarelos na tépala mediana é um caráter importante para distinguir H. rotundifolia de H. limosa.

É nativa, não endêmica e registrada para o Nordeste (MA, PI, BA) e Sudeste (SP, RJ), ocorrendo na Mata Atlântica (Amaral 2012).
3. Pontederia Linnaeus, Sp. Pl. 1: 288. 1753.

Plantas perenes ou anuais, enraizadas, flutuantes ou emergentes. Caule submerso. Folhas sésseis submersas, formando uma roseta basal, flutuantes ou emergentes cordadas, lanceoladas, ovais, oval-cordadas, reniformes, sagitadas. Inflorescência em espiga. Perigônio zigomorfo tubular, alvo, azul e róseo; tépalas oblongas, lanceoladas, ovada-elípticas, elípticas, glandularpubescentes ou pilosas quando emersas. Androceu com seis estames, heterodínamos. Carpelos originalmente 3 unidos, 2 abortados e 1 fértil, unilocular, 1 óvulo. Fruto utrículo ou aquênio.

Gênero heterostílico como Eichhornia, sendo que Pontederia parviflora Alexander é a única espécie homostílica dentro do gênero. Apresenta plasticidade fenotípica, com suas estruturas vegetativas e reprodutivas variando em comprimento e formato. Desta forma, embora descritas diversas variedades, atualmente são aceitas duas, $P$. cordata L. var. cordata e P. cordata L. var. ovalis (Mart.) Solms. (Horn 1987, Faria \& Amaral 2005). Na área estudada ocorre a variedade $P$. cordata L. var. ovalis. Esta diferencia-se da Pontederia cordata var. cordata, especialmente quanto a inflorescência congesta, pedúnculo densamente piloso e o perigônio alvo.

3.1. Pontederia cordata var. ovalis (Mart.) Solms in A. DC. \& C. DC., Monogr. Phan 4:533. 1883.

Figs. 2f-h; 3i-j.

Planta emergente, ca. $90 \mathrm{~cm}$ de altura. Caule ereto com 59-80 cm de compr. Folhas emergentes, lanceoladas, ápice obtuso, base oblonga, cartácea, 9,5-20 × 5-9,9 cm; pecíolo 7-40 × 0,6-1,7 cm, cilíndrico, esponjoso; bainha 11-20 cm de compr. Inflorescência espiga, pilosa, 60-140 flores, ca. 4,5 $\mathrm{cm}$; pedúnculo $2-3 \mathrm{~cm}$ compr., pubescente com tricomas tectores de $5 \mathrm{~mm}$ compr.; escapo 13,5-25 cm compr.; bráctea espatulada, 4-7,1 cm compr. Flores dispostas em grupos de 3-7 ao longo da raque, tépalas alvas com calosidades amarelas no labelo, 3-5 mm. Estames 6, brancos com anteras marrons, 3 filetes ca. $3,5 \mathrm{~mm}$ compr. e 3 ca. 8 $\mathrm{mm}$ compr., anteras oblongas. Gineceu 6-8 $\mathrm{mm}$ compr., estilete 1-5 mm de compr., ovário 2-3 mm compr. Fruto utrículo, 0,9-1 cm compr., oblongo ovado com cristas longitudinais ornamentadas com projeções em ganchos. Semente ca. $4 \mathrm{~mm}$, marrom. Material examinado: Ilha Grande, Ilha do Urubu 15.IX.2011, fl. e fr., H.C.E. Nascimento 130 (TEPB); Cipoal, 15.IX.2011, fl. e fr., H.C.E. Nascimento 131 (TEPB). Parnaíba, Delta do Parnaíba, 22.V.2002, fl. e fr., L.Q. Matias, 359 (EAC). 

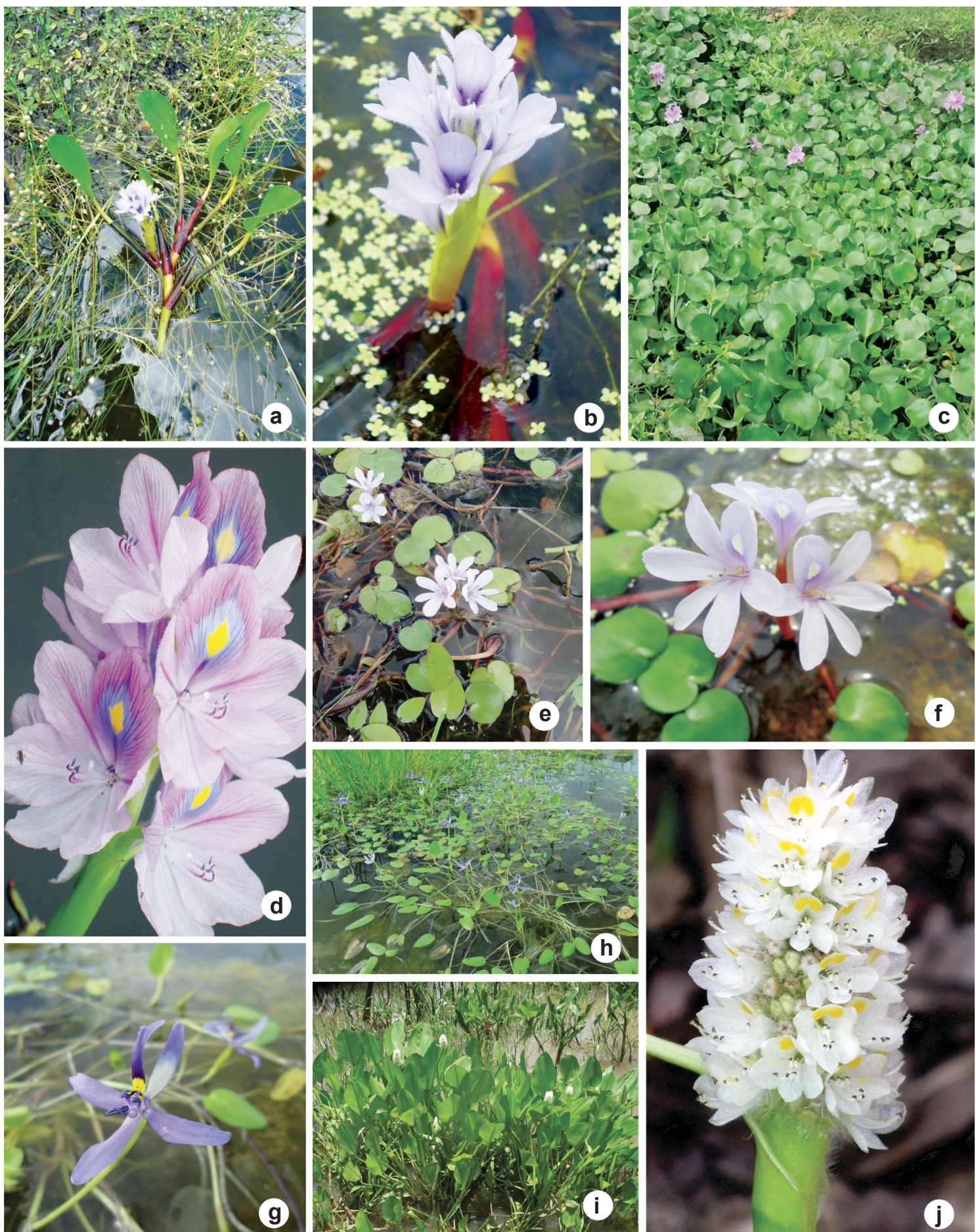

Figura 3 - Pontederiaceae. a-b. Eichhornia azurea (Sw.) Kunth (Silva 2011) - a. hábito; b. detalhe da inflorescência; c-d. Eichhornia crassipes ( Mart.) Solms. (Silva 2011) - c. hábito; d detalhe da inflorescência; e-f. Eichhornia diversifolia (Vahl) Urb. (Silva 2011) - e. hábito; f. detalhe da inflorescência; g-h. Heteranthera rotundifolia (Kunth) Griseb (Melo 2011) - g. detalhe da flor; h. hábito; i-j. Pontederia parviflora Alexandre (Andrade 2011) - i. hábito; j. detalhe da inflorescência. Figure 3 - Pontederiaceae. a-b. Eichhornia azurea (Sw.) Kunth (Silva 2011) - a. habit; b. detail of inflorescence. c-d. Eichhornia crassipes ( Mart.) Solms. (Silva 2011) - c. habit; d. detail of inflorescence. e-f. Eichhornia diversifolia (Vahl) Urb. (Silva 2011) - e. habit; f. detail of inflorescence. g-h. Heteranthera rotundifolia (Kunth) Griseb (Melo 2011) - g. detail of flower; h. habit. i-j. Pontederia cordata var. ovalis L. (Andrade 2011) - i. habit; j. detail of inflorescence. 
Pontederia cordata var. ovalis foi encontrada em lagoas temporárias e igarapés, constituindo populações persistentes em ambientes sazonais e com ampla variação da lâmina d'água. Perfil ecológico semelhante foi registrado por Penha et al. (1988) no Pantanal Mato-grossense, cujas populações apresentam hábito de vida variável e situadas em diferentes gradientes de inundação que compreenderam ambientes permanentemente alagados e periodicamente secos. Os autores também observaram que houve o pico de produção de sementes na cheia, o qual pode maximizar a dispersão de sementes pela água.

A espécie é nativa, não endêmica do Brasil, registrada para o Nordeste (MA, PB e BA), Centro-Oeste (MG, MS), Sudeste (MG, SP) e Sul (GS), ocorrendo na Caatinga, Mata Atlântica e Pantanal (Amaral 2012).

\section{Agradecimentos}

Agradecemos ao CNPq, o suporte financeiro para o projeto Biodiversidade de Macrófitas Aquáticas do Delta do Parnaíba (processo no. 503494-2009-7), ao Sistema de Autorização e Informação em Biodiversidade (ICMBio-SISBIO) e à equipe do projeto, o auxílio nos trabalhos de campo e ao Dr. Simon Mayo do Royal Botanic Gardens, Kew, a revisão do abstract.

\section{Referências}

Albuquerque, B.W.P. de. 1981. Plantas forrageiras da Amazônia. I- Aquáticas flutuantes livres. Acta Amazônica 11: 457-471.

Alves dos Santos, I. 2002. The breakdown of the tristyly system in Eichhornia azurea (Pontederiaceae) and the flower visiting bees in Southeastern Brazil. Biological Journal of the Linnean Society 77: 499-507.

Amaral, M.C.E. 2012. Pontederiaceae. In: Forzza, R.C. et al. (eds.). Lista de espécies da flora do Brasil. Jardim Botânico do Rio de Janeiro. Disponível em < http:// floradobrasil.jbrj.gov.br/2012/FB020612>. Acesso em 4 Mar 2012.

Bove, C.P.; Gil, A.S.B.; Moreira, C.B. \& Anjos, R.F.B. 2003. Hidrófitas fanerogâmicas de ecossistemas aquáticos temporários da planície costeira do estado do Rio de Janeiro, Brasil. Acta Botanica Brasilica 17: 119-135.

Correll, D.S. \& Correll, H.B. 1972. Aquatic and wetland plants of the Southwestern United States. Vol. 2. Stanford University Press, Stanford. 1777p.

Castellanos, A. \& Klein, R.M. 1967. Pontederiaceae. In: Reitz, R. (ed.). Flora ilustrada catarinense. Pars. 1 fasc. Pont. Herbário Barbosa Rodrigues, Itajaí. Pp. $1-28$.
Chaguri, M.P. 2010. Utilização de escamas e Eichhornia crassipes no tratamento de efluente de curtume de peles de tilápias. Dissertação de Mestrado. Universidade Estadual Paulista, Cidade. 65p.

Chaves, T.A.; Ramos, V.M.; Carvalho Júnior, O.A. Martins, E.S.; Gomes, R.A.T. \& Guimarães, R.F. 2007. Delimitação e caracterização das unidades geomorfológicas na Área de Proteção Ambiental (APA) do Delta do Parnaíba utilizando dados morfométricos e imagens do sensor Aster. Espaço \& Geografia 12: 125-149.

Cook, C.D.K. 1998. Pontederiaceae. In: Kubitzki, K. (ed.). The families and genera of flowering plants. Springer-Verlag, Berlim. Pp. 395-403

Cronquist, A. 1981. An integrated system of flowering plants. Columbia University Press, New York. 1262p.

Dahlgren, R.M.T.; Clifford, H.T. \& Yeo, P.F. 1985. The families of the Monocotyledons. Structure, evolution and taxonomy. Springer-Verlag, Berlin.

Faria, A.D. \& Amaral, M.C.E. 2005. Pontederiaceae. In: Wanderley, M.G.L. et al. (eds.). Flora fanerogâmica do estado de São Paulo. Vol. 4. Rima, São Paulo. Pp. 325-330.

Fernandes, A.G. 2000. Fitogeografia brasileira. $2^{\mathrm{a}}$ ed. Multigraf, Fortaleza. 340p.

França, F.; Melo, E.; Góes Neto, A.; Araújo, D.; Bezerra, M.G.; Ramos, H.M.; Castro, I. \& Gomes, D. 2003. Flora vascular de açudes de uma região do semiárido da Bahia, Brasil. Acta Botanica Brasilica 17: 549-559.

Ganders, F.R. 1979. The biology of heterostyly. New Zealand Journal of Botany 17: 607-635.

Gastal Júnior, C.V. de S. 1999. Pontederia cordata L.vs Pontederia lanceolata Nutt. Revista da FZVA Uruguaiana 5/6:101-113.

Graham, S.W.; Kohn, J.R.; Morton, B.R. \& Eckenwalder, J.E. 1998. Phylogenetic congruence and discordance among one morphological and three molecular data sets from Pontederiaceae. Systematic Biology 47: 545-567.

Haynes, R.R. 1984. Techniques for collecting aquatic and marsh plants. Annals of the Missouri Botanical Garden 71: 229-231.

Henry-Silva, G.G.; Moura, R.S.T. \& Dantas, L.L.O. 2010. Richness and distribution of aquatic macrophytes in a Brazilian semi-arid aquatic ecosystems. Acta Limnologica Brasiliensia 22: 147-156.

Heywood, V.H. 1985. Las plantas con flores. Ed. Reverté. $329 \mathrm{p}$.

Holmgren, P.; Holmgren, N.H. \& Barnett, L. 1990. Index Herbariorum. 8th ed. New York Botanical Garden, New York.

Horn, C.N. 1987. Pontederiaceae. In: Spichiger, R. (ed.). Flora del Paraguay. Missouri Botanical Garden, Conservatoire et Jardin Botaniques, Ville de Genève. Pp. 1-28. 
Horn, C.N. 1988. Developmental heterophylly in the genus Heteranthera (Pontenderiaceae) Aquatic Botany 31: 197-209.

Irgang, B.E.; Pedralli, G. \& Waechter, J.L. 1984. Macrófitas aquáticas da Estação Ecológica do Taim, Rio Grande do Sul, Brasil. Roessleria 6: 395-405.

Irgang, B.E. \& Gastal Junior, C.V.S.1996. Macrófitas Aquáticas da Planície Costeira do RS. Ed. dos Autores, Porto Alegre. 290p.

Kingsford, R. T. 1997. Wetlands of the world's arid zones. In: Ramsar Convention on Wetlands, 1971, Ramsar. Dísponível em <http:www.ramsar.org/ about_arid.htm>. Acesso em 29 Nov 2012.

Lowden, R.M. 1973. Revision of the genus Pontederia L. Rhodora 75: 426-487.

Lyra-Lemos, R.P.; Mota, M.C.S.; Chagas, E.C.O. \& Silva, F.C. 2010. Checklist da flora de Alagoas: Angiospermas. Instituto do Meio Ambiente de Alagoas, Maceió.

Martins, L.R. \& Coutinho, P.N. 1981.The Brazilian continental margin. Earth-Science Reviews 17: 87-107.

Matias, L.Q.;Amado, E.R. \& Nunes, E.P. 2003. Macrófitas aquáticas da lagoa de Jijoca de Jericoacoara, Ceará, Brasil. Acta Botanica Brasilica 17: 623-631.

Meerhoff, M.; Rodríguez-Galeno, L. \& Mazzeo, N. 2002. Potencialidades y limitaciones del uso de Eichhornia crassipes (Mart.) Solms en la restauración de lagos hipereutróficos subtropicales. In: Fernández, A. \& Chalar, G. (eds.). Agua en Iberroamérica: de la limnologia a la gestión en Sudamérica. CYTED XVII, Buenos Aires. Pp 61-74

Moretti, M.S.; Goulart, M.D.C. \& Callisto, M. 2003. Eichornia azurea (Swartz) Juanth, 1843 e Pontederia lanceolata Nutt., 1818 (Pontederiaceae) na Baía do Coqueiro, Pantanal de Poconé (MT/ Brasil). Revista Brasileira de Zoociências 51: 7-21.

Neves, E.L.; Leite, K.G.B.; França, F. \& Melo, E. 2006. Plantas aquáticas vasculares em uma lagoa de planície costeira do município de Candeias, Bahia, Brasil. Sitientibus 6: 24-29.

Penha, J.M.F.; Silva, C.J. \& Bianchini-Júnior, I. 1988. Impacto da variação do nível de água no ciclo de vida da macrófita aquática Pontederia cordata var. ovalis (Mart.) Solms, em área alagável do Pantanal Mato-grossense. Brazilian Journal of Ecology on line. Disponível em <http://www. seb-ecologia.org.br/revista2/ind1.html>. Acesso em 5 Dez 2012.

Pott, A. \& Pott, V.J. 1999. Flora do Pantanal, listagem atual de fanerógamas. In: Anais II Simpósio sobre
Recursos Naturais e Socio-econômicos do Pantanal, Corumbá, 1996. Embrapa, Corumbá. Pp. 297-325.

Pott, V.J. \& Pott, A. 1997. Checklist das macrófitas aquáticas do Pantanal, Brasil Acta Botanica Brasilica 11: 215-227.

Ramsar 2010. The annotated Ramsar list: Brazil. Disponível em <http://www.ramsar.org $>$. Acesso em 29 Nov 2012.

Rizzini, C.T. 1997. Tratado de fitogeografia do Brasil. $2^{\text {a }}$ ed. Âmbito Cultural, Rio de Janeiro. 747p.

Rocha, C.G.; Resende, U.M. \& Lugnani, J.S. 2007. Diversidade de macrófitas em ambientes aquáticos do IPPAN na Fazenda Santa Emília, Aquidauana, MS. Revista Brasileira de Biociências 5: 456-458.

Sanches, A.L.; Cervi, A.C. \& Pott, V.J. 2000. Levantamento taxonômico de Pontederiaceae Kunth do Pantanal, nos estados de Mato Grosso e Mato Grosso do Sul, Brasil. In: III Simpósio sobre Recursos Naturais e Sócio-econômicos do Pantanal: os desafios do novo milênio, Cuiabá/MS. 31p.

Simpson, M.G. \& Burton, D.H. 2006. Systematic floral anatomy of Pontederiaceae. In: Columbus, J.T.; Friar, E.A.; Porter, J.M.; Prince, L.M. \& Simpson, M.G. (eds.). Monocots: comparative biology and evolution (excluding Poales). Rancho Santa Ana Botanic Garden, Claremont. Pp. 499-519

Sobral-Leite, M.; Campelo, M.J.A.; Siqueira-Filho, J.A. \& Silva, S.I. 2010. Checklist das macrófitas vasculares de Pernambuco: riqueza de espécies, formas biológicas e considerações sobre distribuição. In: Albuquerque, U.P.; Moura, A.N. \& Araújo, E.L. (eds.). Biodiversidade, potencial econômico e processos ecofisiológicos em ecossistemas nordestinos. Vol. 2. Pp. 253-280.

Sousa, R.S. 2010. Etnobotânica e etnozoologia de comunidades pesqueiras de Área de Proteção Ambiental (APA) do Delta do Parnaíba, Nordeste do Brasil. Tese de Mestrado. Universidade Federal do Piauí, Teresina. 162p.

Takhtajan, A. 1997. Diversity and classification of flowering plants. Columbia University Press, New York. 643p.

Trovó, M. \& Gomes-Silva, F. 2010. Flora da Serra do Cipó, Minas Gerais: Pontederiaceae. Boletim de Botânica da Universidade de São Paulo 28: 87-89.

Veloso, H.P.; Rangel Filho, A.L.R.; \& Lima, J.C.A. 1991. Classificação da vegetação brasileira, adptada a um sistema universal. IBGE, Rio de Janeiro.

Zickel, C.S.; Almeida Jr., E.B.; Medeiros, D.P.W. et al. 2007. Magnoliophyta species of restinga, state of Pernambuco, Brazil. Check List 3:224-241. 